\title{
WARRANTS AGRICOLAS (Armazens Geraes)
}

Em SEguida vae transcripto um disclkso PRONUNCIAdo NA SESSÃo Da Camara dos Deputados deste Estado, pelo dr. Veiga Filho, Lente Cathedratico da Faculdade DE Direito, Sobre a QUestão dos Warrants Agricolas e Armazens Geraes, cujo assumpto É DE TODA aCTUALIDADE.-I2-9-906.

O sR. Veiga Filho-Sr. presidente. O projecto de lei vindo do Senado, sobre armazens geraes e warrants, cujo debate ora se inicia, nesta casa, é de toda opportunidade e do maior alcance pratico para a agricultura. Diversas leis já promulgadas, em annos anteriores, neste Estado, no sentido de auxiliar a lavoura, tão trabalhada por uma crise de ordem permanente, não têm sido corôadas de exito feliz e, para nós, legisladores, ellas são como "fructos da experiencia que se colhem na arvore dos espinhos". 
Trata-se agora de implantar uma utilissima insti. tuição para a qual, por sua vez; já foram frustrados os ingentes esforços dos illustres brasileiros drs. Joaquim Antão, visconde de Itaborahy, Bernardino de Campos e Leopoldo de Bulhões, ministros referendarios dos decretos de I869, I 870, I 897 e I903, sobre armazens geraes e warrants.

Até hoje não foi possivel adaptar-se, em nosso meio economico, aquelle instituto que, inaugurado na Inglaterra por Walpole, só depois de decorridos muitos decennios, de varios insuccessos e grandes difficuldades, foi acclimado em algumas nações da Europa. Em nosso paiz, eu attribúo o facto alludido á imperfeição das leis que, na especie, calcadas principalmente sob o molde juridico, pouco têm de estimulo, de animação e auxilio para não serem mallogradas.

Por outro lado, força é confessar: o assumpto não tem sido largamente discutido, bastando, para comprovar o asserto, o que vou relembrar ácerca da elaboração da lei vigente, no Congresso Nacional, a qual acompanhei com sincero interesse.

Sem prévia justificação, depositado o projecto na mesa da Camara Federal, em sessão de 7 de agosto de I90I, dahi a quasi um anno, isto é, em sessão de 3 I de julho de I902, por occasião da primeira discussão, o dr. Serzedello Corrêa, em ligeiras reflexões, recommendou-o á attenção da Camara, fazendo transcrever, no seu discurso, a integra da brilhante exposição de motivos que, como o alludido projecto, foi obra exclusiva do illustrado dr Carvalho de Mendonça. Nas sessões de i a 5 de agosto seguinte, sem parecer da respectiva commissão, falaram a proposito mui perfunctoriamente, os deputados Affonso Costa e Cornelio da Fonseca, o primeiro fazendo sentir a falta de capitaes para serem empregados nos warrants e portanto 
sem confiança na viabilidade da idéa e o segundo, pretendendo alterar o projecto, de modo que os armazens geraes sómente se destinassem á guarda das mercadorias para o adiantamento de dinheiro pelos respectivos empresarios, á semelhanças das cásas de penhores. Mais tarde, em sessão de 7 de dezembro, o projecto foi ainda alvejado pelo deputado Bricio Filho, que o considerou inconstitucional, por conter isenções de impostos estaduaes e municipaes. Em seguida, porém, foi votado e passou integralmente, sem ser em nada alterado e assim foi remettido para o Senado! Nesta casa esteve durante quasi todo o anno de 1903 e, sem parecer ou discussão alguma, foi successivamente votado nas sessões de 9 e I 4 de novembro, sendo convertido em lei no dia $2 \mathrm{I}$, tudo summariamente, sem que, até hoje, recebesse a consagração pratica da lavoura, da industria e do commercio.

- Contrastando essa lamentavel indifferença, em relação a um assumpto de tamanho valor economico, nós acabamos de presenciar a conducta do Senado paulista que, estudando e discutindo, amplamente, a questão dos armazens geraes e dos warrants, mereceu o applauso de todos, firmando a esperança de, muito breve, termos uma lei perfeitamente exequivel, dentro da economia estadual.

Sendo assim, porque, tomando o precioso tempo desta casa, o orador ainda pretende occupar-se daquella iniciativa do Senado paulista?

(Não apoiados geraes).

O sr. Azevedo Marques - Ouvimos com prazer o nobre deputado que, no assumpto, é muito competente.

O sR. Veiga Filho--Sr. presidente. Pela letra do decr. federal n. I.IO2, de 2 I de novembro de 1903 e dos decretos anteriores ns. 4.450 , de 8 de janeiro 
de I 870 e I.746, de I 3 de outubro de I 869 , do decr. 2.502 , de 24 de abril de 1897 , bem como do projecto em discussão - cogita-se de promover a organisação de armazens geraes, em tudo similares aos da das nações modernas e que tenham por fim mobilizar, não só toda e qualquer mercadoria da industria e do commercio, como quaesquer productos agricolas.

Basta ler o art. I. ${ }^{\circ}$ do projecto para isso verificar-se e, uma vez convertido esse dispositivo em lei, uma empresa, que sómente tenha por fim mobilizar artigos de importação extrangeira, não fica excluida de participar dos favores a ser concedidos. Teremos, então, auxiliado a creação de orgams puramente commerciaes, sem laço algum directo com a lavoura.

Ora, parece-me que não é esse o espirito, não é essa a orientação dominante.

Pelo menos, para mim, eu penso que o intuito do projecto é mobilizar a grande producsaão agricola, e, em tal pé, é necessario, para evitar duvidas futuras e questões juridicas muito graves, limitar o objectivo dos armazens geraes, indicando-lhes um fim exclusivamente agricola, dando-lhes, portanto, um destino especial e unico.

Restringindo esse escopo, isto é, promovendo-se a creação de armazens geraes agricolas para a emissão de warrants agricolas, pelo menos temos reduzido os innumeros embaraços a vencer, e facilitado a execução da idéa.

Sendo assim, na pratica, interpretando a nossa situação economica, podemos crear uma instituição accommodada aos nossos immediatos interesses, vasada no molde juridico das Doks e Magasins Generaux, da França e, quanto ao ponto de vista rural, nos elevadores dos campos, country elevators dos Estados Uni- 
dos e dos kornhauser da Allemanha. Nos elevadores dos campos, porque quando estes não desvirtuam seus fins nas farmers alliance, prestam enormes beneficios como a guarda, o beneficiamento da producção de todas as regiões agricolas da Norte-America, e, quanto aos institutos allemães, porque estes são ainda directamente auxiliados pelo Estado. Estabelecendo aquella distincção preliminar, que me parece capital, ou preferindo-se o systema assim esboçado, será facil assimilar a nova instituição, que, certamente, virá corresponder á uma justa aspiração da lavoura.

Nem se diga que a lei vigente, citada, não permitte essa restriç̧ão, toda no interesse da nossa lavoura, pois no seu art. I. ${ }^{\circ}$, referindo-se ás pessoas naturaes e juridicas que pretenderem estabelecer armazens geraes, deu a estas, e mui claramente, apenas um fim generico, isto é, - a guarda $e$ conservafão das mercadorias - deixando portanto a quem. interessar a escolha dessas mesmas mercadorias e prohibição de outras como, por exemplo, os artigos inflammaveis. Acho não ser preciso insistir neste ponto, tanto mais quanto outras empresas, como a Companhia Docas de Santos, com suas vastas installações e poderosos recursos; por si só, podem e vão satisfazer, por completo, o desideratum commercial, independente da garantia de juros estadual.

Pois, si os armazens, que ora se pretende fundar, são poucos para as exigencias da nosșa enorme producção agricola, da nossa exportação, porque assumir o compromisso legal de egualmente acceitar todos os artigos da importação?! É, pois, neste sentido, a minha primeira emenda e assim irei justificando outras subordinadas a esse aspecto, por que encarei o assumpto.

- Questões connexas ao systema exclusivo do estabelecimento dos armazens agricolas, estão as que 
se referem ao ponto de vista technico. Entre muitas, examinarei duas principaes.

- Sendo o fim de taes instituições-habilitar o lavrador a esperar pela venda de suas colheitas, em occasiões favoraveis - porque não permittir que os productos agricolas, como nos country elevators, sejam não só guardados in corpore, tal como são recebidos-como tambem beneficiados e classificados para a melhor conservação dos mesmos e emissão dos warrants?

Embora o dispositivo do art. I 2, $\mathbb{I} .^{\circ} \mathrm{n}$. I da lei declare que o armazem não é obrigado a restituir a propria mercadoria, podendo entregar mercadorias da mesma qualidade, porque motivo, nós, que ora estamos estabelecendo um regimen contractual, não completamos os intuitos do decreto legislativo federal, fazendo tão util, tão necessaria especificação? A um lavrador convirá, sómente, a guarda de sua producção agricola, com a declaração da respectiva qualidade regional ou local--a outro, mandar classifical-a, de accôrdo com os typos adoptados, para operar sobre ella. Porque não preencher ambos esses requisitos?

Note, sr. presidente, que pela letra da lei, (art. I 5 combinado com o art. I 2) o armazem geral não pode deixar de adoptar os typos commerciaes em voga, para elles emittir os warrants e terem estes firme, facil e ampla circulação. E' essa, em certos artigos, a mistura de que fala a lei. Exemplifiquemos, quanto ao café.

Os nove typos americanos são hoje os adoptados em nossas praças e toda a lavoura conhece-os.

Pois bem, como emittir o warrant, para circular livremente, si em tal titulo não constar a qualidade do café? O legislador, quando se referiu á qualidade das mercadorias, certamente não teve em vista a infinita 
variedade productiva local-mas a variedade dos mercados, isto é, as qualidades da base, adoptadas ou consagradas pelo uso ou trato mercantil das praças.

Agora, quanto ao beneficiamento de certos productos como o café. Qual o motivo por que o projecto 'não permitte que se beneficiem os artigos de producção agricola? Nos elevadores do Norte-America, bem como nos kornhauser da Allemanha, os diversos serviços technicos exigidos para o completo beneficiamento e acondicionamento dos productos agricolas, são executados mediante uma remuneração extremamente modica. Como diz L. Scansa, em seu classico livro "Traité des Magasins Generaux», os armazens Saint Denis, de Paris, beneficiam os artigos de producção agricola alli depositados, precedendo pedido das partes interessadas. Que bom auxilio não será para a lavoura si the facultarmos essa vantagem? Por outro lado ter-se-á proporcionado mais elementos de renda para os armazens, tornando-se menos provavel a effectividade da garantia de juros.

Nesta ordem de idéas, elaborei outra emenda, permittindo aos armazens, não só operarem sobre os artigos de producção agricola, que forem especificados no respectivo regulamento da lei, recebidos e guardados in corpore - como os que tiverem de ser beneficiados, classificados e acondicionados, para a formação dos typos commerciaes. No primeiro caso, será for. necido ao lavrador um certificado, ou conhecimento de simples deposito, correspondente ao weigh-note; no segundo caso, além de certificado ou conhecimentoo titulo do sale-warrant ou do warrant propriamente dito, pois, nada impede que ambos os titulos existam unièos ou separados. O dr. Carvalho de Mendonça, auctor da lei vigente sobre armazens, na exposição de motivos, que publicou, é partidario dessa faculdade 
concedida a taes estabelecimentos que della poderão usar, quando a pedido dos interessados.

Si não examinarmos detidamente os pontos ora indicados e mais outros como a conveniente localização dos armazens, a questão das garantias de juros para o periodo que effectivamente funccionarem e não permanecerem paralysados, a questão da disseminação delles, por isso que a garantia não se refere a dez institutos no valor maximo de 400 contos, como parece a questão das tarifas e muitas outras, não teremos com a brevidade que desejamos esse importante melhoramento agricola.

Sem ficar bem esclarecidas todas as duvidas que têm sido suscitadas, esses institutos não poderão desempenhar entre nós o grandioso fim, que no dizer do illustrado senador Mello Peixoto:- "não é tão sómente realizar a guarda e a conservação das mercadorias que ahi forem depositadas: a lei lhes assignala outras e mais importantes funç̧ões por meio das quaes, multiplicando o credito, facilitando a mobilização das mercadorias, poupando despesas, evitando desembolsos aos depositantes, graduando a entrada da producção nos mercados e permittindo ao productor escolher o momento da venda de seus generos - têm sido esses estabelecimentos convertidos em maravilhoso instrumento de commercio entre os povos adeantados da Europa e da America."

-Agora, sr. presidente, seguindo o plano do projecto, seja-me licito fazer mais algumas reflexões sobre a emissão, circulaşão e o vencimento do warrant.

Que é o warrant? Segundo os tratadistas como MaURin e Brouillet o warrant, no sentido ordinario da palavra, é um titulo representativo tendo por destino especial substituir a coisa na operação do penhor: 
materialmente, é uma simples folhà de papel que symboliza a mercadoria representada; juridicamente, é um effeito do commercio.

O warrant agricola, emittido não sobre mercadoria, mas sobre productos da lavoura, ainda não entregues ao commercio ou ao consumidor, tem os mesmos caracteristicos. Será um effeito agricola.

$\mathrm{O}$ dr. Albuquerquie Lins, que tamanho empenho sempre tem ligado á questão, discutindo o credito agricola na outra casa do Congresso, em sessão de 20 de março de 1903 , disse:- $" \mathrm{O}$ warrant, bem sabemos todos, é um titulo de credito do lavrador, com o warrant o lavrador faz dinheiro, sem precisar dispôr da producção agricola sob a pressão dos preços do momento.?

Acceitando essa exacta noção, aliás de perfeita harmonia com as idéas que venho sustentando, eu me contentarei apenas em symbolizar esse utilissimo instrumento de circulação e que um brilhante papel vem representar entre nós, dizendo apenas:-O warrant é o primeiro degrau do credito agricola!

Isto posto e convencido de que, em face da lei e do nosso projecto; só aos armazens compete emittir taes titulos, deixando de parte a questão da publicidade dessa hypotheca movel, resta-me inquirir:- quaes os productos que podem ser objecto do warrant agricola?

Este assumpto, que, á primeira vista, parece facil, se me afigura da maior complexidade, sobretudo pela justa e exacta enumeração dos productos agricolas. Em geral, tres são as condições a preencher para que os productos sejam considerados aptos para o warrant: r. ${ }^{\circ}$ - a sua enumeração legal; $2 .^{\circ}-\mathrm{a}$ sua proveniencia; $3 .^{\circ}$ - a sua natureza.

Inspirando-me na lei franceza de 18 de julho de I 898, sobre warrants agricolas e na respectiva circular 
de 16 de agosto do mesmo anno, do Ministerio da Justiça, parece-me que, entre nós, os productos agricolas devem ser os seguintes:- café, fumo, algodão em bruto; arroz, milho e cevada; forragens; materias textis animaes e vegetaes; vinhos, alcooes ou aguardente; madeiras; pelles; couros; oleos vegetaes; todos de producsãa da lavoura do Estado.

Uma classificação impõe-se, si é que vamos crear armazens exclusivamente destinados á agricultura. E tal classificação não póde deixar de excluir muitos artigos agricolas, como, por exemplo, o gado e outros, pois, só, no correr do tempo, é que será ampliado o circulo da applicação da lei. Não tendo feito sinão uma indicação summaria, sem alludir á questão de ser ou não necessaria a deslocaçãa dos referidos artigos e isso para apenas justificar a minha terceira emenda - eu passarei a fazer breves ponderações sobre a circulafãa do warrant agricola.

-A maior objeç̧ão que, por vezes, tenho visto formular-se, quanto á circulasãa do warrant agricola, é relativa á falta de um instituto de credito especialmente organizado para só operar com os lavradores.

O exito dos armazens entre nós, na verdade, muito ou em tudo depende da existencia de um instituto de credito, especialmente organizado, para o desconto do warrant, além de outros effeitos agricolas; sem o banco não se terá apparelhado os elementos para o lavrador esperar pela venda.

Eu tambem participo desse modo de pensar e receio o insuccesso da lei, comquanto francamente infenso áquelles, que, em face dessa incerteza, contrariando a indole de taes instituições, querem dar aos armazens geraes a faculdade de operar sobre os respectivos titulos emittidos. 
Alguns amigos com que tenho conversado a respeito deste ponto, procuram dissuadir-me dessa desconfiança, fazendo vêr que alguns armazens para serem organizados pela iniciativa particular, apenas esperam pela lei que estamos projectando.

Outros argumentam com a fixação do cambio prestes a ser decretada pelo Congresso Nacional e que incontestavelmente virá facilitar não só o exodo do capital extrangeiro para S. Paulo, como a immediata execução da lei estadual n. 923, de 8 de agosto de i 904, que transformou em ouro as garantias dadas para a fumdação de um grande banco de credito agricola.

Estes motivos fizeram-me deixar de apresentar uma desenvolvida emenda nesse sentido, e em tudo de accôrdo com um bello parecer, ha annos apresentado pelo meu amigo dr. Joaquim Miguel de Siqueira, á Sociedade Paulista de Agricultura.

-Quanto ao vencimento do warrant agricola, deixando de referir-me ás hypotheses ou incidentes que pódem surgir por occasião do pagamento antecipado da novação, do abatimento voluntario, da compensação, da confusão, do pagamento na data estipulada ou da respectiva quitação - eu tomarei em' linha de conta a hypothese da liquidação judicial, pelo não implemento da primeira condição, isto é, do pagamento no dia aprazado.

O senador Mello Peixoto, em seu parecer emittido na outra casa do Congresso, salientou as facilidades proporcionadas pela lei vigente para a liquidação judicial do warrant agricola. Realmente, basta ler o art. 23 e seus $\mathbb{S}$, para ter-se, do que fica dicto, uma perfeita conviç̧ão. $\mathrm{Ha}$, porém, um lado pratico assaz interessante e que o projecto deve cogitar e prevenir

Refiro-me ao logar onde deve ser realizado o leilão dos productos agricolas depositados para a garantia da solvabilidade do devedor ou do warrant emittido. 
Supponhamos a liquidação judicial de um warrant agricola, emittido sobre 50.000 saccas de café, por uma empresa com séde em Ribeirão Preto, Jahú e Campinas, os municipios mais productores do paiz.

Ora, ha alguem que desconheça as enormes difficuldades da venda desse artigo em um leilão onde são raros os licitantes? Ha alguem que conteste ser a praça de Santos ou de S. Paulo as unicas naturalmente indicadas para a séde dos leilões, de modo a evitar maior prejuizo dos interessados lavradores? (Muito bem. Muito bem).

Nessa conformidade eu formulei a minha $4^{a}$ emenda ao projecto e não mais proseguirei neste importante ponto, porque espero ter occasião de discutil-o, conjunctamente com a questão das Bolsas ou das vendas publicas e do mercado livre, a termo, que ora se constituiu em Santos, augmentando a offerta do café e offerecendo á lavoura os maiores perigos.

Sr. presidente. O apparelho que o projecto vai crear, preenchendo uma grande lacuna; em nosso meio rural, não é propriamente um elemento de defesa, nesta ingente lucta da valorização do principal artigo da produç̧ão paulista. Este instrumento preliminar, do credito agricola, ou melhor, essa poderosa organização, segundo todos os tratadistas, é principalmente um apparelho de resistencia da lavoura.

Embora retida por circumstancias excepcionaes, transitorias, para não ser precipitadamente vendida, a producção agricola seguirá sempre o seu destino, que é a sahida para os grandes centros de distribuição e de consumo. Si a actual crise não puder ser inteiramente resolvida por meio dos armazens e dos warrants agricolas, é incontestavel que taes institutos 
virão representar um grande papel para minorar os grandes soffrimentos da lavoura. Ha mais de um decennio que os optimistas nos prophetizam o fim proximo da crise agricola e cada vez ella mais se aggrava e mais se extende de anno a anno! Um escriptor allemão, fazendo o mesmo reparo para uma situação identica á nossa, accrescenta que «devemos vêr nesse facto, não um phenomeno passageiro, mas um phenomenu, por assim dizer, constante, que revoluciona toda a vida economica e social». Não é difficil perceber que, considerado, sob o ponto de vista economico, o Estado de São Paulo atravessa um periodo identico de completa transformação, como attesta entre outros factos a lei da limitação das culturas, deante de um desperdicio de forças, de uma producção desordenada.

Essł transformação ainda se manifesta: na lavoura pela diffusão do ensino agricola, pelas innovações no regimen do trabalho e innumeros alvitres tendentes á reducção do custo da producção; na industria, pela crescente introducção de machinas; no commercio, pelos infalliveis processos da propaganda; na vida social, pela acção inicial dos syndicatos e cooperativas; na politica, pela legislação rural, cujo periodo activo ora se accentúa.

Tão grande obra renovadora dos methodos agricolas ou modificadora de habitos tradicionaes.

O sr. Azevedo Marques - E do espirito de rotina.

$\mathrm{O}$ SR. Veiga Fil.ho - não se realiza em tres tempos, entre risos e flores.

«Os povos não differem dos homens. Ha uma coisa que nelles não se transmitte: é aquelle saber feito de experiencia, como diz Camões. Esse ganha-se á propria custa, vivendo e labutando.» 
Eis, sr. presidente, a observação final que me suggere a nossa actual situação economica, a proposito do projecto que discutimos para a creação dos armazens e warrants agricolas, que os maicres beneficios virão trazer para a lavoura do Estado.

Vozes-Muito bem! Muito bem! (O orador é felicitado). 